EDUCATION AND TRAINING

\title{
Promoting health care safety through training high reliability teams
}

\author{
K A Wilson, C S Burke, H A Priest, E Salas
}

Qual Saf Health Care 2005;14:303-309. doi: 10.1136/qshc.2004.010090

Many organizations have been using teams as a means of achieving organizational outcomes (such as productivity and safety). Research has indicated that teams, especially those operating in complex environments, are not always effective. There is a subset of organizations in which teams operate that are able to balance effectiveness and safety despite the complexities of the environment (for example, aviation, nuclear power). These high reliability organizations (HROs) have begun to be examined as a model for those in other complex domains, such as health care, that strive to reach a status of high reliability. In this paper we analyse the components leading to the effectiveness of $\mathrm{HRO}$ s by examining the teams that comprise them. We use a systems perspective to uncover the behavioral markers by which high reliability teams (HRTs) are able to uphold the values of their parent organizations, thereby promoting safety. Using these markers, we offer guidelines and developmental strategies that will help the healthcare community to shift more quickly to high reliability status by not focusing solely on the organizational level.

See end of article for authors' affiliations

Correspondence to: Ms K A Wilson, Institute for Simulation and Training, University of Central Florida, 3100 Technology Parkway, Orlando, FL 32826, USA;

kwilson@ist.ucf.edu

Accepted for publication 12 June 2005
(Part 121, Scheduled Air Carriers) experienced no fatal accidents in 2002 and only two fatal accidents in 2003 resulting in 22 deaths (www.ntsb. gov). This number is relatively small considering the millions of passengers who travel each year.

Due to their excellent safety records and continued effectiveness, HROs have received an increasing amount of attention within the past 10 years, and other organizations such as those in health care-for example, pediatric cardiac surgery units ${ }^{7}$-have strived to evolve to high reliability status. ${ }^{8}$ While the study of HROs is increasing, ${ }^{9}$ limited within this work is the idea that other components within organizations can and should be viewed as high reliability systems (for example, teams ${ }^{10}{ }^{11}$ ). Given the research evidence that strongly argues as to the importance of teams within organizations, ${ }^{12}$ it is surprising that teams operating within HROs have not been more readily studied in this manner.

There are three key areas that must be integrated to create a safe work environment: organizational factors, team factors, and developmental strategies (fig 1). This figure serves as a framework on which this paper is organized. While the focus of the paper is to assist the healthcare community as they evolve to high reliability status, the information provided can be applied to other organizations as well. The objectives of this paper are threefold. We briefly discuss the organizational factors that together create the foundation and mindfulness necessary to reach high reliability status. It is important to recognize that the organization alone cannot achieve this status, so we argue that teams within the organization must also act as high reliability entities. Because this has not been discussed extensively in the literature, we then describe the requisite team behavioral markers as well as how they serve to promote the organizational values held by HROs. Using these behavioral markers, we conclude the paper with literature based guidelines and developmental strategies that will help healthcare organizations to shift more quickly and smoothly to high reliability status.

\section{WHAT ARE HIGH RELIABILITY ORGANIZATIONS (HROS)?}

HROs function within hazardous environments and have been characterized as complex and tightly coupled. ${ }^{13}$ While some authors have argued that HROs are no different from other organizations (see Roberts ${ }^{13}$ for a discussion),

Abbreviations: CRM, crew resource management; $\mathrm{HRO}$, high reliability organization; HRT, high reliability team 


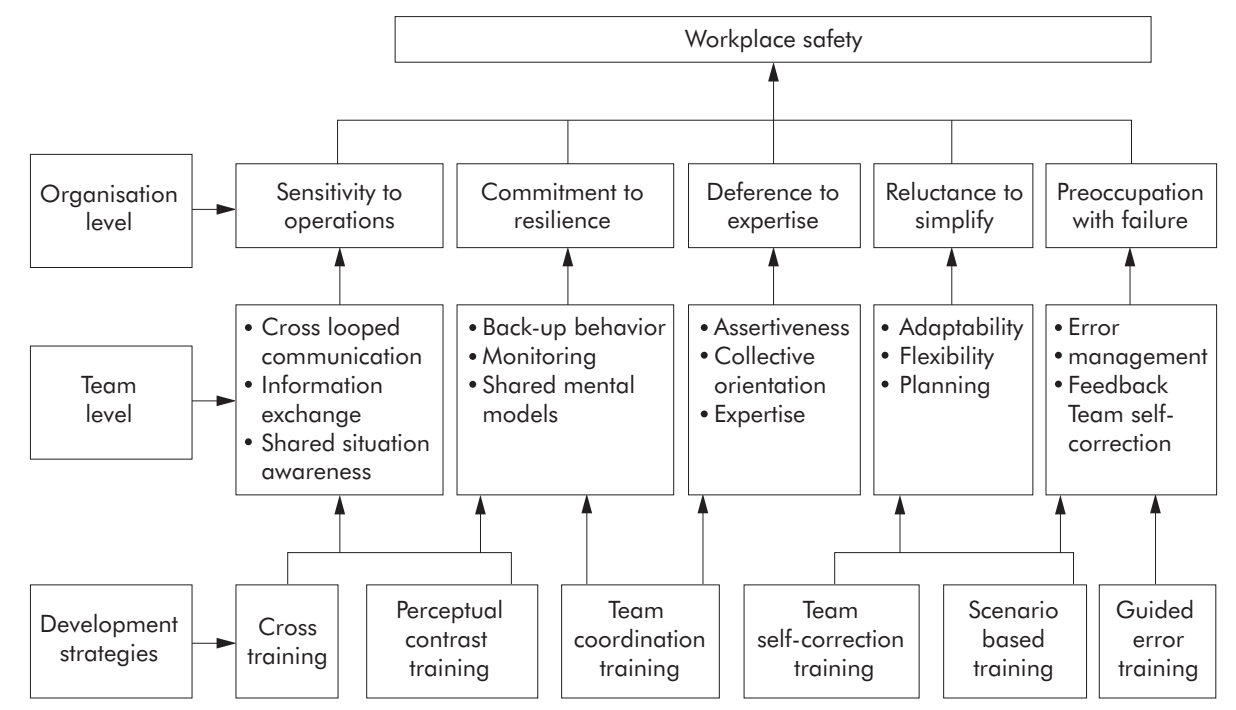

Figure 1 Structure for promoting safety in the workplace.

this is less likely the case. In addition to working within perilous environments, researchers have argued that what sets HROs apart from others is how they operate internally. ${ }^{8}$ Specifically, it is suggested that the HROs' "mindfulness" or their ability to exhibit "a pattern of heedful interrelations of actions" ( $p$ 357) has allowed them to reach their high reliability status. Furthermore, and as depicted in fig 1, mindfulness at the organizational level is comprised of a commitment to certain values and actions-specifically, commitment to resilience, sensitivity to operations, deference to expertise, reluctance to simplify, and preoccupation with failure $^{9}$ (see table 1 for definitions). Finally, in addition to holding the values previously mentioned, HROs enhance their commitment to excellence by (1) actively seeking knowledge about what they don't know, (2) designing reward systems that recognize both the cost of failures and the benefits of reliability, and (3) communicating the whole picture to all levels of the organization..$^{15}$ Thus, the successful combination of these values and characteristics allows HROs to reduce and mitigate errors in an effort to maintain safety.

\section{WHAT ARE HIGH RELIABILITY TEAMS (HRTs)?}

While much has been learned about teams within the last two decades, the examination of how teams can be used to reduce errors and promote workplace safety (such as patient safety) has been relatively neglected. In order for organizations within the healthcare community (and others) to reach a high reliability status, it takes more than just appropriate organizational level values (for example, commitment to resilience, sensitivity to operations). Rather, a systems view must be taken to look at other levels within the organization that contribute to its high reliability status. Specifically, individuals and teams embedded within the organization are critical to the success of an HRO. Teams in the healthcare community that may be considered HRTs include (but are not limited to) surgical teams, emergency room teams, emergency response teams (such as Emergency Medical Services (EMS)), or any set of two or more team members who consistently and effectively work interdependently towards a shared goal in a complex environment.

Extracting from the literature on HROs and HRTs, it can be argued that, to become an HRT, team members must exhibit behaviors that facilitate those characteristics and values held by the organization within which they operate. The team level behaviors critical for the success of HROs at maintaining their status and achieving workplace safety will be discussed next. While the teamwork behaviors described are those that may be exhibited by non-HRTs, HRTs differ in that they are able to demonstrate these behaviours consistently and effectively over time in complex dynamic environments while working under high levels of stress. We discuss these team behaviors in terms of how they contribute to organizational values and conclude each section with a prescription for achieving high reliability status.

\section{Sensitivity to operations}

- Guideline I: HRTs must use closed loop communication and other forms of information exchange to promote shared situational awareness regarding factors internal and external to the team.

HRTs help organizations maintain a sensitivity to operations by ensuring that all team members know the "big picture". Closed loop communication and well developed shared situation awareness are key within this type of environment. Closed loop communication consists of the team's ability to exchange clear concise information, to acknowledge receipt of that information, and to confirm its correct understanding. ${ }^{16}$ When doctors prescribe medications for patients, it is critical that the nurse acknowledges that the request has been received and that the doctor verifies that the correct prescription is being obtained. Similarly, as a patient is transferred from one department to another (for example, from EMS to the emergency room), it is important that all of the necessary information (such as "vitals") is transmitted and received accurately. In addition, HRTs exhibit shared situation awareness of the environment, allowing them to apply the appropriate task strategies, ${ }^{17}$ which is foundational to the evolution of high reliability status. A shared awareness of the situation among team members helps to improve workplace safety by alerting members to latent errors, as well as impacting decisions in terms of strategy and team coordination efforts to contain and minimize errors that do occur. ${ }^{17}{ }^{18}$ For example, a surgical team with shared situation awareness can anticipate future contingencies before they escalate into a more critical situation.

\section{Commitment to resilience}

- Guideline 2: HRTs must develop shared mental models that allow team members to monitor others' performance and offer back-up assistance when needed. 
Table 1 Values exhibited by high reliability organizations (HROs) and high reliability teams (HRTs)

\begin{tabular}{ll}
\hline Value & Organization level \\
\hline $\begin{array}{l}\text { Sensitivity to } \\
\text { operations }\end{array}$ & Ongoing concern with the unexpected
\end{tabular}

operations

Attentiveness to those on the front line

Acknowledgement that the cause of an accident is often not the result of a single active error but rather errors lying latent in the system

Sources: Weick and Sutcliffe, ${ }^{9}$ Roberts and $\mathrm{Bea}^{15}$

Commitment to resilience

Ability to identify, control, and recover from errors

Errors and failures kept small

Practice worst case scenarios

Develop general strategies to expect and react to the unexpected Source: Weick and Sutcliffe?

Deference to Encourages communication of expertise expertise from all levels

Decisions made on the front line

Cultivate diversity

Source: Weick and Sutcliffe?

Reluctance to Unwillingness to simplify a situation simplify

Create more complete pictures of situations

Encourage spanning of boundaries, negotiating, scepticism, and differences in opinions

Source: Weick and Sutcliffe ${ }^{9}$

Preoccupation with Encourage error reporting failure

Accept human error as inevitable

Obsession with success liabilities (e.g. overconfidence)

Source: Weick and Sutcliffe ${ }^{9}$

\section{Team level}

Closed loop communication: Team's ability to exchange information accurately and clearly and to acknowledge receipt of information (e.g. during shift change, outgoing nurse informs incoming nurse of patients' status. Incoming nurse summarizes that information and outgoing nurse confirms its accuracy).

Information exchange: Team members' ability to speak clearly, concisely, and in an unambiguous manner with other team members (e.g. an EMS technician provides vital signs of incoming patient to emergency room team). Information exchange skills should be transportable, meaning improvement in their ability to communicate increases across tasks. Shared situation awareness: Team's ability to develop shared mental models of the environment (internal and external) to apply correct task strategies and anticipate future situations (e.g. a surgical team discusses "if-then" scenarios prior to the procedure).

Sources: Cannon-Bowers et $a{ }^{17}{ }^{17}$ Endsley ${ }^{18}$

Back-up behavior: The capability of team members to give, seek and receive task instructive feedback. Assisting team members to perform their tasks. Back-up behavior can be achieved by providing a team mate with verbal feedback or coaching, helping a team mate behaviorally in carrying out actions, and/or assuming and completing a task for a team mate (e.g. a doctor offers assistance to another doctor during an emergency to reduce workload). Performance monitoring: Team's ability to monitor team members' performance and provide constructive feedback (e.g. a nurse monitors a doctor's performance during a procedure to ensure steps are not omitted).

Shared mental models: Team's ability to share compatible knowledge pertaining to individuals' roles in the team, the roles of fellow team members, their characteristics, and the collective requirements needed for effective team interaction (e.g. a surgical team has a shared and overlapping understanding of the procedure to be performed). Sources: Cannon-Bowers et al, ${ }_{17}^{7}$ Dickinson and Mclntyre

Assertiveness: The willingness of team members to communicate ideas and observations in a manner that is persuasive to other team members. Allows team members to provide feedback, state and maintain opinions, address perceived ambiguity, initiate actions, and offer potential solutions (e.g. a nurse questions a doctor's medication order because of a patient's known allergies).

Collective orientation: Some team members have been found to be more collectively oriented than others, meaning they exhibit more interdependent behaviors in task groups (e.g. all ER team members worked together to solve the challenging problem).

Expertise: Knowing how to do something well and is gained through experience (e.g. the ER team required the expertise of all members to identify the cause of a patient's unusual symptoms).

Sources: Roberts and Bea, ${ }^{15}$ Helmreich and Merritt, ${ }^{19}$ Blickensderfer, ${ }^{27}$ Smith-Jentsch et al ${ }_{1}^{52}$ Smith et $a^{53}$

Adaptability/flexibility: Team's ability to gather information from the task environment and adjust their strategies by reallocating their resources and using compensatory behaviors such as back-up behavior (e.g. a stable patient goes into cardiac arrest and the team must respond quickly).

Planning: Planning both prior to and during a mission helps teams improve performance by setting goals, sharing relevant information, clarifying member's roles, prioritizing tasks, discussing expectations, and environmental characteristics and constraints (e.g. prior to the arrival of a critical patient to the emergency room, the attending resident discusses roles, responsibilities, and expectations for when the patient arrives).

Sources: Cannon-Bowers et $a l_{,}^{17}$ Stout et $a^{54}$

Error management: Based on understanding the nature and extent of error, changing conditions found to induce error, and determining and training behaviors that decrease errors (e.g. an emergency room team recognizes that an inappropriate drug has been administered and quickly takes actions to mitigate the consequences).

Feedback: Team's ability to provide constructive feedback, seek feedback on own performance, and accept feedback from others (e.g. following surgery, the lead surgeon provides a debriefing of the surgery including positive aspects and areas in need of improvement).

Team self-correction: Team's ability to monitor and categorize their own behavior to determine its effectiveness, which generates instructive feedback so that team members can review performance episodes and correct deficiencies (e.g. surgical team meets following a procedure to discuss positive and negative aspects of procedure and ways to improve performance in the future).

Sources: Cannon-Bowers et al, ${ }_{17}^{17}$ Helmreich $^{55}$

EMS, Emergency Medical Services. 
The consequences of errors in HROs are severe. It has therefore been argued that the greatest countermeasure to human error is collaboration among team members (that is, teamwork). ${ }^{19}$ HRTs encourage a commitment to resilience in that members serve as redundant systems to avoid, trap, and mitigate the consequences of errors. ${ }^{19}$ In order to prevent errors and ensure workplace safety, team members must do several things: (1) ask for help when overloaded, (2) monitor each others' performance to notice any performance decreases, and (3) take an active role in assisting other team members who are in need of help (for example, lending a hand; expressing diverse viewpoints). To accomplish this, HRTs demonstrate teamwork behaviors such as mutual performance monitoring, back-up behavior, and development of shared mental models. ${ }^{17} 20$ For example, ER nurses and doctors must be willing to work together to ensure that patients are handled efficiently and safely. This includes monitoring each others' performance and providing assistance (back-up behavior) when one is overloaded. In addition, by developing a shared understanding of the situation and task at hand, the team is able to work together more efficiently without having explicitly to state expectations. Rather, team members know what to do and when, and each team member completes his/her task and provides relevant information without being asked. A lack of clear understanding can have detrimental consequences, and this contributed to an incompatible heart-lung transplant that was performed at Duke University in $2003 .{ }^{21}$

\section{Deference to expertise}

- Guideline 3: HRTs must demonstrate a collective orientation that allows members to be assertive, to take advantage of functional expertise, and to seek and value input from other team members.

Many teams use status or member rank to determine how heavily to weigh the advice or input that members offer. HRTs, however, defer to member expertise by recognizing its value regardless of the level at which it resides. HRTs are also aware that the knowledge or actions of one team member are important and must be taken into consideration. ${ }^{22} 23$ Furthermore, the team has a collective orientation in that what another team member knows or does impacts on the rest of the team. Additionally, as it may not always be senior team members who have the most expertise in a given situation; it is important for junior members to feel comfortable speaking up and offering their expertise. As such, junior team members are encouraged to assert themselves (that is, clearly and directly communicate their concerns and ideas to others) and to share their expertise with the team. ${ }^{24}$ For example, a nurse should feel comfortable addressing a concern to the doctor without fear of reprimand, even if the concern was unwarranted. Deference to expertise allows HRTs to take full advantage of the potential synergy available within the team in any given situation, regardless of rank.

\section{Reluctance to simplify}

- Guideline 4: HRTs must seek to recognize complexities of their task environment and accordingly develop plans that are adaptable and promote flexibility.

An environment simplified by expectations can help reduce the complexity and promote coordination among HRT members. However, if simplified too much, it can also affect workplace safety in that information may be excluded or ignored. It is important in these environments that HRTs be prepared to recognize and react to both expected (routine) and unexpected (such as novel) events.' A surgeon, for example, who is not prepared for a potential hemorrhage in the patient while in the operating room can seriously jeopardize the patient's life. HRTs accomplish a reluctance to simplify by careful planning before and while conducting a task, creating expectancies of what will occur. ${ }^{9}$ It is standard procedure for aviation crews to conduct a preflight briefing before departing on a flight. The briefing includes information pertaining to each member's roles and responsibilities, route of flight, emergency procedures, and other relevant expectations. In addition, during periods of low workload, HRTs (like those in aviation) continue to plan for contingencies that may occur. ${ }^{25}$ However, expectations can "color" one's attention and interpretation of informationthat is, information perceived as consistent with expectations is valid and inconsistent information is not valid-and thus, the actions taken based on the information. Inflexible expectations can lead to disconfirming, ignoring, or misinterpreting evidence. HRTs must therefore remain flexible and adaptable to all situations to ensure workplace safety.

\section{Preoccupation with failure}

- Guideline 5: HRTs must use semi-structured feedback mechanisms such as team self-correction to manage, trap, and quickly learn from errors.

Errors occur within systems every day; however, many are trapped before an accident occurs. Klair, ${ }^{26}$ speaking of the aviation industry, states that: "lessons can ... be learned from flights that do not end in accidents" (p 72) as they provide clues into what errors are occurring and how they are managed. HRTs use techniques such as team self-correction to learn from their mistakes. Self-correction entails team members monitoring their own and other's behavior during an event followed by a non-accusatory discussion of positive and negative examples of teamwork that occurred (after action review). ${ }^{27}$ As part of the self-correction process, HRTs provide, seek, and accept constructive feedback. ${ }^{17}$ Providing feedback on the positive and negative aspects of the task at its completion (such as after surgery) allows team members to reflect on what was done correctly and what needs to be improved to ensure safety of the workplace. Preoccupation with failure in HRTs is also evidenced by the encouragement of team members to report incidents that did not result in a reportable accident. Such methods taken to encourage this type of reporting are voluntary non-punitive reporting systems-for example, US Aviation Safety Reporting System, ASRS; UK National Reporting and Learning System. Reports from the system should be analyzed ${ }^{28}$ and used to train HRTs on how to manage and handle nonroutine events proactively. ${ }^{29}$ The aviation industry has greatly benefited from the implementation of this nationwide reporting system, and the healthcare community could also benefit from such a system. Some have argued, however, that underreporting of adverse events in the US is very high (up to $96 \%$ go unreported each year $\left.{ }^{30}\right)$. Furthermore, the culture within the healthcare community and a fear of litigation may impede the reporting of failures. ${ }^{31}$ Whether one life is at risk in the healthcare industry or hundreds of lives in the aviation domain, failures should be reported so that they can be learned from and prevented in the future.

\section{HOW CAN TEAMS IN HEALTH CARE EVOLVE TO HIGH RELIABILITY STATUS?}

As previously mentioned, teams are a widely used strategy for improving workplace safety, ${ }^{19}{ }^{32}$ especially in health care. We believe that HROs demonstrate characteristics to create an overall mindfulness through the use of HRTs. Therefore, as the healthcare community is striving to reach a status of high reliability, it becomes important to consider how healthcare 
teams can make this shift as well. The characteristics found to be indicative of promoting safety at an organizational level and their translation into behaviors needed by HRTs are shown in fig 1 . These characteristics are supported through the organization (for example, by leadership and support from upper level management) and training, and ultimately lead to workplace safety. By following the science of training and systematically designing and implementing instructional strategies, ${ }^{33}{ }^{34}$ non-HRTs are better able to make the shift to high reliability status. Using the information contained within the previously discussed guidelines, we can begin to propose how to develop non-HRTs in the healthcare community into HRTs through a number of developmental training strategies (table 2).

\section{Developmental strategy 1: Cross training}

In order to operate as an HRT, it is important that team members are able to anticipate and support other team members in their tasks (such as by providing back-up behavior). Failures in care can occur when team members have different understandings of what they should be doing in relation to what their fellow team members are doing. If all team members (such as nurses and doctors) have a shared understanding of the roles of the other, the risk for error is decreased. To do this, teams must be provided with cross training which gives them a clear understanding and shared representation (shared mental model) of how the team

Table 2 Developmental strategies for transforming nonhigh reliability teams into high reliability teams

\begin{tabular}{|c|c|}
\hline $\begin{array}{l}\text { Developmental } \\
\text { strategy }\end{array}$ & Definition \\
\hline Cross training & $\begin{array}{l}\text { Team members are able to gain a clear } \\
\text { understanding and shared representation (shared } \\
\text { mental model) of how the team functions as well as } \\
\text { how each individual's tasks and responsibilities are } \\
\text { interrelated to those of other team members. }\end{array}$ \\
\hline $\begin{array}{l}\text { Perceptual contrast } \\
\text { training }\end{array}$ & $\begin{array}{l}\text { Team members are actively involved in learning in } \\
\text { order to create a deeper and more acute } \\
\text { understanding of the instructional material. }{ }^{56} \text { Team } \\
\text { members may be required to actively compare the } \\
\text { defining characteristics of contrasting cases which } \\
\text { will give them a keener understanding of the } \\
\text { concepts. }\end{array}$ \\
\hline $\begin{array}{l}\text { Team coordination } \\
\text { training }\end{array}$ & $\begin{array}{l}\text { Team members improve skills such as team } \\
\text { coordination, communication (both explicit and } \\
\text { implicit), and back-up behaviour. }{ }^{58} \text { Practice } \\
\text { opportunities are also provided for additional } \\
\text { competencies that lead to effective coordination. }\end{array}$ \\
\hline $\begin{array}{l}\text { Team self-correction } \\
\text { training }\end{array}$ & $\begin{array}{l}\text { Team members are taught to assess the } \\
\text { effectiveness of their own behavior and that of } \\
\text { others. }{ }^{27}{ }^{43} \text { Team members are also taught how to } \\
\text { provide constructive feedback and correct deficient } \\
\text { behaviors. }\end{array}$ \\
\hline $\begin{array}{l}\text { Scenario based } \\
\text { training }\end{array}$ & $\begin{array}{l}\text { Team members are given an opportunity to } \\
\text { experience critical learning events (such as } \\
\text { common instances where errors and unsafe } \\
\text { behaviors are occurring) embedded in the training } \\
\text { scenarios, allowing them to learn from a } \\
\text { meaningful framework. }{ }^{34} 44\end{array}$ \\
\hline $\begin{array}{l}\text { Guided error } \\
\text { training }\end{array}$ & $\begin{array}{l}\text { Team members are able to experience errors, react } \\
\text { to errors, and see the consequences of errors } \\
\text { through guided practice (Lorenset et al, } \\
\text { unpublished). }{ }^{47} 49 \text { Errors are used as a function of } \\
\text { information that provide feedback to trainees so } \\
\text { they may develop better learning and knowledge } \\
\text { transfer strategies to be used in the real task } \\
\text { environment. }\end{array}$ \\
\hline
\end{tabular}

functions as well as how each member's tasks and responsibilities are interrelated to those of others. ${ }^{35}$ There are three levels of cross training: ${ }^{36}(1)$ positional clarification (general knowledge regarding position and associated responsibilities); (2) positional modeling (general dynamics of the team, other team members' duties, and how own duties relate to and affect others), and (3) positional rotation (working knowledge of the specific job activities of others and how own duties interact with and affect others). The appropriate level of training will depend on the level of interdependency and technical expertise required by team members. For example, teams provided with positional rotation training will be able to assist a team member by actually completing his/her task if that team member is overloaded. Consider a nurse who is a designated "floater" (that is, works in several different units). After cross training, this nurse will be able to fill in for another nurse in any of these units if someone is sick or needs assistance. Cross training allows teams to be more effective and efficient. It is important to remember when cross training team members that they should be provided not only with what behaviors should be performed but also "how" and "why" they are performed. This stems from research indicating that, because of the complexity of each other's tasks in the healthcare domain, decreased performance may occur in cross trained individuals as the result of a trade-off between specialized individual skills for broader team skills. ${ }^{37}$ With this knowledge, teams are better able to coordinate without explicit communication (for example, to provide back-up behavior without being asked) to support safety in the workplace through sensitivity to operations and commitment to resilience-characteristics of HRTs.

\section{Developmental strategy 2: Perceptual contrast training}

Cognitive skills such as noticing, performance monitoring, and situational awareness are argued to be important in creating safe mindful HRTs. Perceptual contrast training has been argued to improve one's conceptual knowledge and "noticing" ${ }^{\prime 38}$ by presenting contrasting alternatives to scenarios or events allowing trainees to recognize these differences (contrasts) and discriminate between the positive and negative aspects of each. ${ }^{39}$ For example, trainees could be shown examples of how a surgeon successfully and unsuccessfully leads his/her team in the operating room. As a second example, trainees could be presented with scenarios demonstrating a complete and accurate shift change briefing versus an incomplete and inaccurate shift change briefing. While primarily used at an individual level within relatively confined environments, we argue that this technique can be extended to evolve non-HRTs into HRTs. Expertise demonstrated by HRTs is evidenced by their ability to notice relevant and sometimes subtle differences in both visual and verbal situations. ${ }^{39}$ Noticing and situational awareness are particularly important in hospitals or other emergency environments where there are multiple inputs and little time to make decisions. As noticing is a precursor to the listed cognitive skills, perceptual contrast training may be a way to move teams toward a commitment to resilience, sensitivity to operations, and ultimately safe practices in the workplace.

Developmental strategy 3: Team coordination training Research suggests that high performance teams such as HRTs may use different coordination strategies from low performance teams, ${ }^{40}$ leading to improved safety. For example, the introduction of team coordination training in the aviation community (crew resource management, CRM) has led to improved safety records and fewer accidents resulting from poor teamwork. ${ }^{41}$ CRM training is provided to all team members and focuses not only on the inevitability of human 
error but also on the manageability of those errors through teamwork. Anesthesia crisis resource management, based on CRM training, has been developed in the healthcare community but is limited in that only anesthetists and nurses are provided with training (Wilson-Donnelly et al, unpublished); surgeons, for example, are not. The MedTeams project was also developed to implement CRM training in emergency medical care. ${ }^{42}$ Healthcare professionals must be aware of the potential for failures in complex environments where they are expected to be error-free due to the life and death decisions that must be made. Team members can become more vigilant in these situations by raising awareness of the potential for errors and developing strategies for how teams can learn from them. We argue that, by training the importance of teamwork and team performance, non-HRTs will be better able to communicate and coordinate as a team, reducing the likelihood of errors (through a commitment to resilience and sensitivity to operations) and move closer to becoming a HRT. Training should include creating awareness that expertise may reside within any member, facilitating the team's continuous stride for deference to expertise.

\section{Developmental strategy 4: Team self-correction training}

It is important for HRTs to monitor their situation continuously in an effort to identify non-routine or unsafe behaviors before they culminate into hazardous situations. However, it is not enough that these behaviors are identified; they must also be corrected and avoided in the future. Team self-correction training focuses on teaching team members to identify errors and unsafe behaviors, provide constructive feedback, and correct any unsafe acts so that teams will be more effective during future events. ${ }^{43}{ }^{44}$ A benefit of team self-correction training is that it teaches teams to self-correct without help from an outside instructor. ${ }^{27}$ During training, however, a facilitator plays a key role by: (1) focusing the team's discussion, (2) creating a positive learning climate, (3) encouraging participation from all team members, and (4) modeling skills of effective feedback. ${ }^{43}$ This facilitated training will help prepare teams to complete the selfcorrection process on their own. Teams can then use this strategy during debriefing sessions following task completion (for example, after action reviews within the military). Since a lot of knowledge in health care is based on informal on-thejob training, the ability to self-correct (that is, to identify and correct any weaknesses) can lead to greater expertise and fewer problems as team members learn. These elements help HRTs to maintain their reluctance to simplify and preoccupation with failure. Furthermore, the ability of a team to selfcorrect is important as it evolves from non-high reliability to high reliability status.

\section{Developmental strategy 5: Scenario based training}

Scenario based training is a developmental strategy that uses embedded "trigger" events to structure and guide practice training scenarios. ${ }^{45-47}$ The trigger events serve to elicit specific behaviors which are defined a priori. Designing appropriate practice scenarios and embedding appropriate trigger events allows HRT members to develop the requisite knowledge, skills, and attitudes needed to deal with errors. Scenario based training thus enables healthcare teams to practice for complex and/or novel events that may otherwise be dangerous for the patient or impractical on the job. For example, an EMS team could be presented with a scenario in which they have been called to the scene of a car crash. When they arrive at the scene they identify the family involved in the accident. It appears that all of the family members are okay when the father falls to the ground unexpectedly. The team must adapt quickly and respond to the patient. Performance is observed and feedback provided to improve the team's performance in the future. Thus, providing teams with the opportunity to practice within these types of scenarios allows them to be better prepared to manage a multitude of situations (such as non-routine events or team failures) by remaining adaptive and flexible. In turn, this training allows HRTs to maintain a preoccupation with failure and a reluctance to simplify.

\section{Developmental strategy 6: Guided error training}

Guided error training, which uses a supported error correction technique, has been argued to be most beneficial for reducing and managing errors (Lorenzet et al, unpublished). The premise of guided error training is that training is designed to guide trainees towards making errors so that they can learn what the outcomes of such actions look like. ${ }^{48}$ Once trainees are guided to the errors, they are given support to correct the errors through the development of corrective strategies. ${ }^{49}$ They are then able to apply the learned knowledge and strategies during practice scenarios. Feedback is provided to trainees to help them transfer what they have learned to the real world environment (Lorenzet et al, unpublished). ${ }^{50}$ In the healthcare domain, it has been shown that human error is occurring at alarming rates. ${ }^{2}{ }^{3}$ The need for teams in health care to learn what errors look like and be trained on how to correct them is imperative. As HRTs strive to maintain a preoccupation with failure, guided error training allows non-HRTs to make the shift to high reliability status by training them how to recognize and correct errors when they occur so as to minimize the consequences of such errors.

\section{CONCLUSIONS}

The literature examining HRTs is minimal. However, as organizations increasingly use teams as a means to improve safety, the need to recognize what characteristics should be demonstrated by these teams becomes apparent. The literature available on HROs and HRTs must be extended and applied to HRTs to better understand the characteristics of these teams, how they impact on workplace safety, and how to evolve non-HRTs into HRTs through training. As many organizations in health care are striving to make the shift to high reliability status, this need becomes evident. We hope that the theoretical framework and suggestions that flow from the information provided in this paper will stimulate thinking by the researcher and practitioner communities within health care and beyond. It is important to mention, however, that success will be limited if any of the instructional strategies suggested are used in isolation or if not all team members are provided with training. To have the most significant impact it is necessary to implement multiple

Key messages

- High reliability teams can help organizations become high reliability organizations.

- High reliability teams exhibit closed loop communication, information exchange, shared situation awareness, back-up behavior, mutual performance monitoring, shared mental models, assertiveness, collective orientation, expertise, adaptability, flexibility, planning, error management, feedback, team selfcorrection.

- High reliability teams can be developed by cross training, perceptual contrast training, team coordination training, team self-correction training, scenario based training, and guided error training. 
strategies to all team members to help non-HRTs make the shift successfully.

\section{ACKNOWLEDGEMENTS}

The authors thank Dr Robert Wears from the University of Florida Health Science Center, Jacksonville, Florida, for his clinical insight and suggestions made to this paper.

\section{Authors' affiliations}

K A Wilson, C S Burke, H A Priest, E Salas, Department of Psychology and Institute for Simulation and Training, University of Central Florida, Orlando, Florida, USA

\section{REFERENCES}

1 Reason J. Human error. New York: Cambridge University Press, 1990.

2 Kohn LT, Corrigan JM, Donaldson MS. To err is human: building a safer health system. Washington, DC: National Academy Press, 2000

3 Jaklevic MC. AMA group to look at quality issues. Modern Healthcare 1997;27:27-8.

4 Helmreich RL, Merritt AC. Safety and error management: the role of crew resource management. In: Hayward BJ, Lowe AR, eds. Aviation resource management. Aldershot: Ashgate, 2000:107-19.

5 Mearns KJ, Flin R. Assessing the state of organizational safety-culture or climate? Current Psychology: Developmental, Learning, Personality 1999;18:5-17.

6 Wilson KA. Priest HA, Salas E, et al. Can training for safe practices reduce the risk of organizational liability? In: Noy I, Karwowski W, eds. Handbook of human factors in litigation. New York, Taylor \& Francis, 2005 (in press).

7 Carthey J, de Leval MR, Wright DJ, et al. Behavioural markers of surgical excellence. Saf Sci 2003:41:409-13.

8 Weick KE, Roberts KH. Collective mind in organizations: heedful interrelating on flight decks. Admin Sci Q 1993;38:357-81.

9 Weick KE, Sutcliffe KM. Managing the unexpected: assuring high performance in an age of complexity. San Francisco: Jossey-Bass, 2001.

10 La Porte T, Consolini, P. Theoretical and operational challenges of "highreliability organizations": air traffic control and aircraft carriers. Int J Public Admin 1998;21:847-52.

11 Knox GE, Simpson KR. Teamwork: the fundamental building block of high reliability organizations and patient safety. In: Youngberg BJ, Hatlie MJ, eds. The patient safety handbook. Sudbury, MA: Jones \& Bartlett, 2003:379-414.

12 Guzzo RA, Dickson MW. Teams and organizations: recent research on performance and effectiveness. Ann Rev Psychol 1996;47:307-38.

13 Roberts KH. Managing high reliability organizations. Calif Manage Rev 1990;32:101-13.

14 Perrow C. Normal accidents: living with high-risk technologies. New York: Basic Books, 1984.

15 Roberts KH, Bea R. Must accidents happen? Lessons from high-reliability organizations. Acad Manage Exec 2001; 15:70-9.

16 McIntyre RM, Salas E. Measuring and managing for team performance: emerging principles from complex environments. In: Guzzo R, Salas E, eds. Team effectiveness and decision making in organizations. San Francisco: Jossey-Bass, 1995: 149-203.

17 Cannon-Bowers JA, Tannenbaum SI, Salas E, et al. Defining team competencies and establishing team training requirements. In: Guzzo R, Salas $\mathrm{E}$, Associates, eds. Team effectiveness and decision making in organizations. San Francisco, CA: Jossey-Bass, 1995:333-80.

18 Endsley MR. Situation awareness in aviation systems. In: Garland DJ, Wise JA eds. Handbook of aviation human factors. Human factors in transportation. Mahwah, NJ: Lawrence Erlbaum Associates, 1999:257-76.

19 Helmreich RL, Merritt AC. Error and error management, Technical Report No 98-03. University of Texas Aerospace Crew Research, 1998.

20 Xiao Y, Moss J. Practices of high reliability teams: observations in trauma resuscitation. In: Proceedings of the Human Factors and Ergonomics Society 45th Annual Meeting. Santa Monica, CA: Human Factors and Ergonomics Society, 2001:395-9.

21 Molter J. Review of blood type mismatch for Jesica Santillan continues, Available at: http://dukemednews.duke.edu (accessed 21 February 2003)

22 Driskell JE, Salas E. Can you study real teams in contrived settings? The value of small group research to understanding teams. In: Swezey EW, Salas E, eds. Teams: their training and performance. Stamford, Ablex Publishing Corp, 1992:101-24.

23 Driskell JE, Salas E. Collective behavior and team performance. Hum Factors 1992;34:277-88.

24 Jentsch F, Smith- Jentsch KA. Assertiveness and team performance: more than "just say no. In: Salas E, Bowers CA, eds. Improving teamwork in organizations: applications of resource management training. Mahwah, NJ Lawrence Erlbaum Associates, 2001:73-94.

25 Orasanu J. Shared mental models and crew decision-making, CSL Technical Report No 46. Princeton, NJ: Princeton University, Cognitive Sciences Laboratory, 1990.

26 Klair MB. The mediated debrief of problem flights. In: Dismukes RK, Smith GM, eds. Facilitation and debriefing in aviation training and operations. Aldershot: Ashgate, 2000:72-92

27 Blickensderfer EL, Cannon-Bowers JA, Salas E. Theoretical bases for team self-correction: fostering shared mental models. In: Beyerlein M, Johnson D,
Beyerlein S, eds. Advances in interdisciplinary studies in work teams series. Vol 4. Greenwich, CT: JAI Press, 1997:249-79.

28 Orlady HW, Orlady LM, eds. Human factors in multi-crew flight operations. Aldershot: Ashgate, 1997.

29 Sexton JB, Thomas EJ, Helmreich RL. Error, stress, and teamwork in medicine and aviation: cross sectional surveys. Br Manage J 2000;320:745-9.

30 Barach P, Small SD. Reporting and preventing medical mishaps: lessons from non-medical near miss reporting systems. BMJ 2000;320:759-63.

31 Lawton R, Parker D. Barriers to incident reporting in a healthcare system. Qual Saf Health Care 2002;1 1:15-8.

32 Ilgen DR. Teams embedded in organization: some implications. American Psychologist 1999;541:129-39.

33 Salas E, Cannon-Bowers JA. The science of training: a decade of progress. Ann Rev Psychol 2001;52:471-99.

34 Salas E, Cannon-Bowers JA. Designing training systems systematically. In: Locke EA, eds. The Blackwell handbook of principles of organizational behavior. Malden, MA: Blackwell Publisher, 2000:43-59.

35 Volpe CE, Cannon-Bowers JA, Salas E, et al. The impact of cross-training on team functioning: an empirical investigation. Hum Factors 1996;38:87-100.

36 Travillian KK, Volpe CE, Cannon-Bowers JA, et al. Cross-training highly interdependent teams: effects on team process and team performance. In: Proceedings of the 37th annual meeting of the Human Factors and Ergonomics Society. Santa Monica, CA: Human Factors and Ergonomics Society, 1993:1243-7

37 Cannon-Bowers JA, Salas E, Blickensderfer E, et al. The impact of crosstraining and workload on team functioning: a replication and extension of initial findings. Hum Factors 1998;40:92-101.

38 Lesgold A, Rubinson H, Feltovich $\mathrm{P}$, et al. Expertise in a complex skill: diagnosing $x$-ray pictures. In: Chi MT, Glaser R, eds. The nature of expertise. Hillsdale, NJ: Lawrence Erlbaum Associates, 1988:311-42.

39 Bransford J, Franks J, Vye N, et al. New approaches to instruction: because wisdom can't be told. In: Vosniadou S, Ortony A, eds. Similarity and analogical reasoning. Cambridge, MA: Cambridge University Press, 1989:470-97.

40 Serfaty D, Entin EE, Johnston JH. Team coordination training. In: CannonBowers, JA, Salas E, eds. Making decisions under stress: implications for individual and team training. Washington, DC: American Psychological Association, 1998:221-45.

41 Salas E, Burke CS, Bowers CA, et al. Team training in the skies: does crew resource management (CRM) training work? Hum Factors 2001;43:641-74.

42 Morey JC, Simon R, Jay GD, et al. Error reduction and performance improvement in the emergency department through teamwork training: evaluation results of the MedTeams project. Health Serv Res 2002;37:1553-81

43 Smith-Jentsch KA, Zeisig RL, Acton B, et al. Team dimensional training: a strategy for guided team self-correction. In: Cannon-Bowers, JA, Salas E, eds. Making decisions under stress: implications for individual and team training. Washington, DC: American Psychological Association, 1998:271-97.

44 Stout RJ, Cannon-Bowers JA, Salas E. The role of shared mental models in developing team situational awareness: Implications for training. Training Res J 1996;2:85-116.

45 Fowlkes JE, Dwyer DJ, Oser RL, et al. Event-based approach to training (EBAT). Int J Aviat Psychol 1998;8:209-221.

46 Prince C, Oser R, Salas E, et al. Increasing hits and reducing misses in CRM/ LOS scenarios: Guidelines for simulator scenario development. Int J Aviat Psychol 1993;3:69-82.

47 Oser RL, Cannon-Bowers JA, Salas E, et al. Enhancing human performance in technology-rich environments: guidelines for scenario-based training. In: Salas E, eds. Human/technology interaction in complex systems. Vol 9. Greenwich, CT: JAI Press, 1999:175-202

$48 \mathrm{Karl} \mathrm{KA}, \mathrm{O}^{\prime}$ Leary-Kelly AM, Martocchio JJ. The impact of feedback and selfefficacy on performance in training. J Organis Behav 1993;14:379-94.

49 Carlson RA, Lundy DH, Schneider W. Strategy guidance and memory aiding in learning problem-solving skill. Hum Factors 1992;34:129-45.

50 Frese $M$, Altman $A$. The treatment of errors in learning and training. In: Bainbridge L, Quintanilla SA, eds. Developing skills with information technology. Chichester: John Wiley, 1989:65-86.

51 Dickinson TL, Mclntyre RMA. Conceptual framework for teamwork measurement. In: Brannick MT, Salas E, Prince C, eds. Team performance assessment and measurement: theory, methods, and applications. Mahwah, NJ: Lawrence Erlbaum Associates, 1997:19-43.

52 Smith-Jentsch K, Salas E, Baker DP. Training team performance-related assertiveness. Personnel Psychol 1996:49:909-36.

53 Smith EM, Ford JK, Kozlowski SWJ. Building adaptive expertise: Implications for training design strategies. In: Quinones MA, Ehrenstein A, eds. Training for a rapidly changing workplace: applications of psychological research. Washington, DC: American Psychological Association, 1997:89-118.

54 Stout RJ, Cannon-Bowers JA, Salas E, et al. Planning, shared mental models, and coordinated performance: an empirical link is established. Hum Factors 1999;41:61-71.

55 Helmreich RL. On error management: lessons from aviation. BMJ 2000;320:781-5.

56 Schwartz DL, Bransford JD. A time for telling. Cogn Instruct 1998; 16:475-522.

57 Bowers CA, Blickensderfer EL, Morgan BB Jr. Air traffic control specialist team coordination. In: Smolensky MW, Stein, ES, eds. Human factors in air traffic control. San Diego, CA: Academic Press, 1998:215-36.

58 Entin EE, Serfaty D. Adaptive team coordination. Hum Factors $1999 ; 41: 312-25$ 